\title{
Electronic Health Record Acceptance: A Descriptive Study in Zahedan, Southeast Iran
}

\author{
Jahanpour Alipour, Leila Erfannia*, Afsaneh Karimi and Ali Aliabadi
}

Instructor of health information technology, health information technology department, Allied Health School of Zahedan, University of Medical Sciences, Iran

\begin{abstract}
Electronic Health Record (EHR) is a necessary tool for providing uninterrupted flow of information about the health of population. The role of physicians cannot be overemphasized in the implementation of EHR; therefore, the purpose of this study is to determine the physician's attitude towards the acceptance of EHR project. In this regard, a descriptive analytical study was carried out in 2011; however, sampling was done by convenience sampling method that includes 70 physicians of public hospitals affiliated to Zahedan University of Medical Sciences. Data collection was made through a self-administered questionnaire and data processing was done using descriptive statistics and analysed by Oneway ANOVA and One-sample t-test. The factors affecting acceptance of electronic health record by physicians were determined as follows: management support $4.01 \pm 0.60$, physician involvement $4.06 \pm 0.51$, adequate training $4.04 \pm$ 0.51 , physician autonomy $3.20 \pm 0.61$, doctor-patient relationship $2.33 \pm 0.82$, perceived usefulness $3.91 \pm 0.46$ and attitude about electronic health record acceptance $4.03 \pm 0.46$. Physician's attitude towards Electronic Health Record acceptance was determined in optimal level. In order to facilitate successful adoption of electronic health record, involvement of physicians would be essentially required during the EHR designing, implementation and usage phase.
\end{abstract}

Keywords: Electronic health record; Physician; Acceptance

\section{Introduction}

Electronic health record (EHR) is a long-life repository of health information that is essentially required for maintaining a personal health profile of country's population [1]. EHR contains past, present and future health information with the aim to support continuity, efficiency and quality of integrated health care [2]. Electronic medical records can be accessible from multiple locations and units, so the time of accessing patient medical record is reduced and also the productivity will increase and the quality of care will improve [3] reducing medical errors, conserving physician time, sharing patient information among healthcare practitioners and workflow efficiency are some benefits that identified for EHR systems [4] by making electronic health care information available with EHR at the point of patient care, lots of lives could be saved [5] in contrast, technical issues, misalignment of cost and benefits or financial reimbursement, concern about privacy and confidentiality and lack of health information data standards are the major barrier to adoption of an electronic health record system [4]. EHR implementation is a long-term and complex project that needs more investment and detailed planning. Mostly the experiences about this project reveal the intricacy of EHR in its implementation and few other related problems such as progress of project at snail's pace, difficulties in using strategies, partial acceptance or resistance by health staff and fear of return on investment [6]. High cost of project and lack of complete products also add the gravity of problems [7].

In a study, which was conducted by Medical Records Institute (MRI), the essential problems in EHR implementation were highlighted as lack of financial resources, low medical community support, high cost of EHR systems, and complexity in EHR evaluation, EHR ownership and transformation from paper to electronic records [6]. Better output on health care system would be achieved by effective usage and acceptance of information technology by clinicians. So far the results acquired through the study manifest that even most renowned and safety-oriented clinicians do not make use of health information technology in true letter and spirit rather under-utilize it on areas, which assume secondary importance [8]. Professionals all over the world have realized the potential power of computer-based medical records. In United States, 83\% Ambulatory Care Practice and $90 \%$ of the hospitals do not have electronic medical records [9].

The main key factor for eagerly acceptance of electronic medical record is its friendly usage for physicians, nurses and other clinical professionals. If the electronic system is frequently practiced, it would tend to attract many physicians to use electronic medical records [9]. Jabraily et al. [10] in a research about EHR implementation in Tabriz, Iran reports that Tabriz Medical University's staffs not ready to implement EHR.

Success in implementation will depend on various factors such as users' respond to the new system [11]. Daniel in a national study reflected that EHR user acceptance for both house staff physician and faculty physician was as high as 88 and $64.7 \%$ respectively [12]. Sitting suggested that physicians' reluctance is one of the major barrier in realizing the EHR capabilities [7]. Current health care reforms have laid more emphasis on EHR as an efficient means in exchanging the health information [13]. Physicians as a key coordinator and health care provider, EHR acceptance by them is one of the deciding factors towards total success of EHR implementation. Health care organizations should make elaborate preparations for managing the challenges that would emerge with the implementation of new information system [14]. Also there are few evidences that show the failure of EHR implementation as a reason of little attention or involvement of physicians [15]. Some researches argue about the negative view of faculty and residents

*Corresponding author: Leila Erfannia, Instructor of health information technology, health information technology department, allied health school of Zahedan, University of Medical Sciences, Zahedan, Iran, Tel: +989171163017, E-mail: Leila.erfannia@gmail.com

Received November 11, 2012; Accepted December 20, 2012; Published December 26, 2012

Citation: Alipour J, Erfannia L, Karimi A, Aliabadi A (2013) Electronic Health Record Acceptance: A Descriptive Study in Zahedan, Southeast Iran. J Health Med Inform 4: 120. doi:10.4172/2157-7420.1000120

Copyright: (c) 2013 Alipour J. This is an open-access article distributed under the terms of the Creative Commons Attribution License, which permits unrestricted use, distribution, and reproduction in any medium, provided the original author and source are credited. 
toward EHR [9]. Communication with physicians and managers is a vital factor because lack of correct communication would be one of the contributing factors in failure of information system. Rejection of EHR by physicians would result in compounding problems for clinical information system therefore prior evaluation of the attitude towards information system would predict the future individual reaction towards the new systems [14].

Successful implementation of EHR requires persuasion of clinical professionals' involvement in designing and revising the system, this process will lead to a continuous feedback from physician in pre, current and post phase of EHR implementation. Thus, role of physician is essentially anticipated in all phases of implementation of EHR.

The electronic health (e-health) and electronic records were taken in Iran during 2001 and examined mainly by ministry of health, medical education and the organization of Iran social services [16]. Presently, computers are being used at different levels in Iranian hospitals. In most of the cases, hospitals have installed Hospital Information System (HIS) that can support EHR [17] Zahedan, based in southeast Iran started implementing HIS in public hospitals since 1996 and now infrastructures are being prepared for EHR implementation. The study would determine the physicians' attitudes that work in public hospitals affiliated to Zahedan University of Medical Sciences and identify the factors affecting their acceptance of electronic health record project.

\section{Materials and Methods}

This descriptive analytical study was conducted in 2011 at public hospitals affiliated to Zahedan University of Medical Sciences and its statistical population was physicians (faculty and non-faculty) who work at 5 public hospitals in Zahedan, based in southeast Iran. We used convenience method sampling for data collection and distributed 70 questionnaires to 5 public hospitals for evaluating our research goals. At first, we translated the questionnaire in Persian, for reliability of questionnaire; we used test-retest method. We circulated our questionnaire in one hospital and after 20 days we collected them. The test-retest reliability was measured by Pearson correlation coefficient $(\mathrm{r}=0.84 \%)$. Thereafter, validity of questionnaire was certified by some of electronic health and clinical professionals. The answer range was distributed in 5 scales ( 1 to 5 scores) from completely agree to disagree. It had also 3 major sections. First part was related with demographic information; second part had some questions about using computer, information system and history of computer training. Third part contained 40 questions ( 7 of them were about management support, 5 were about physician involvement, 4 about physician training, 7 about physician autonomy in using EHR, 4 about physician- patient communication and 7 about perceived usefulness and 6 about physician attitude about EHR acceptance). At the end, 3 questions were about the proposed methods for training, physician and administrative managers on agreement about EHR implementation.

For gathering of data, we visited 5 public hospitals and explained questionnaire to the physicians. After one week, we again contacted hospitals and collected the questionnaire. Thereafter, we imported the collected data to SPSS software for processing. Not withstanding, each question that got $75 \%$ score (mean of 3.75 from 5) considered as an optimal situation and the score under this range was non optimal. We deliberately analyzed the result by using Descriptive Statistics and parameters such as Frequency, mean and standard deviation and also statistical test such as One-sample T-test and One-way ANOVA and illustrated them at 4 tables.

\section{Results}

According to our study, 61.7\% (47 persons) of our research population were men and $32.9 \%$ (23) were women. Most of them were at the age ranging between $30-39,13 \%$ (9) under 30 and the other had more than 40 years old. $37 \%$ percent (26) had lower than 5 years' experience and $63 \%(44)$ had more than 5 years. Nearly half responders (57\%) were faculty members, $23 \%$ (16) residents and $20 \%$ were not faculty member. $88.6 \%$ (64) suggest group training, $7.1 \%$ (5) individual training and $4.3 \%$ (3) suggests the other method for electronic health record training. Almost one-third (31.4\%) think that physicians had agreed about electronic health record, $52.9 \%$ (37) disagree on this project and $15.7 \%$ had no idea about agreement.

From all respondents, $45.7 \%$ (32) of physicians expressed their consent or management agreement towards EHR implementation, 18.6\% (13) got disagreed and 35.7\% (25) had no knowledge about management agreement on EHR implementation.

About physician usage from computer, majority of them (81.4\%) were used from computer for finding of health and clinical resources, journal or researches (Table 1).

The other factor that assess, was use of information system in physician workplace, most of them (31.4\%) have never used information system in their work (Table 2).

About $68.5 \%$ of physician means most of them, had self-guided learning about training or experience with computer (Table 3).

Physician attitude about EHR acceptance had a mean score more than 3.75 so we can say they are in optimal situation $(p<0.05)$. EHR effect on physician-patient relationship and physician autonomy has a mean score under 3.75 because the questions in this section have negative meaning. According to One way ANOVA between attitude of responders to EHR implementation and professional specialty for all sections except physician-patient relationship, there wasn't any significant relationship. Between participants and their age in perceived

\begin{tabular}{|l|c|c|}
\hline Usage & Frequency & Percent \\
\hline Patient health information & 19 & 27.14 \\
\hline Personal email & 53 & 75.7 \\
\hline Health and clinical resource, journal or researches & 57 & 81.4 \\
\hline
\end{tabular}

Table 1: Frequency Distribution of Physician (usage from computer).

\begin{tabular}{|l|c|c|}
\hline Use of information system & Frequency & Percent \\
\hline I use the information system frequently in my work. & 15 & 21.4 \\
\hline I use the information system occasionally in my work. & 28 & 40 \\
\hline $\begin{array}{l}\text { I have used information system in the past but I am not } \\
\text { using it currently in my work. }\end{array}$ & 2 & 2.8 \\
\hline $\begin{array}{l}\text { I have never used the information system in my work. } \\
\begin{array}{l}\text { I have used an information system in a facility other than } \\
\text { here. }\end{array}\end{array}$ & 22 & 31.4 \\
\hline
\end{tabular}

Table 2: Frequency Distribution of Physician (use of information system).

\begin{tabular}{|l|c|c|}
\hline Type of experience with computer & Frequency & percent \\
\hline Formal medical school training in computer & 14 & 20 \\
\hline Formal residency or fellowship training in computer & 7 & 10 \\
\hline $\begin{array}{l}\text { Formal workshops or conference on computers for which I } \\
\text { receive CME credit }\end{array}$ & 7 & 10 \\
\hline $\begin{array}{l}\text { Workshop or conference on computer for which I didn't } \\
\text { receive CME credit }\end{array}$ & 5 & 7.14 \\
\hline Self-guided learning about computers & 48 & 68.5 \\
\hline
\end{tabular}

Table 3: Frequency Distribution Training or Experience with Computer. 


\begin{tabular}{|l|c|c|c|}
\hline & Mean \pm SD & T & P-VALUE \\
\hline $\begin{array}{l}\text { Management support in EHR implementation and } \\
\text { organizational climate. }\end{array}$ & $0.60 \pm 4.01$ & 3.62 & 0.001 \\
\hline $\begin{array}{l}\text { Physician involvement during the implementation } \\
\text { phase of EHR project. }\end{array}$ & $0.51 \pm 4.06$ & 5.08 & 0.001 \\
\hline Physician training about how to use EHR. & $0.51 \pm 4.04$ & 4.76 & 0.001 \\
\hline Physician autonomy about using EHR. & $0.61 \pm 3.20$ & -7.41 & 0.001 \\
\hline EHR effect on doctor patient relationship & $0.82 \pm 2.33$ & -14.30 & 0.001 \\
\hline Physician perceived usefulness & $0.46 \pm 3.91$ & 3.01 & 0.004 \\
\hline $\begin{array}{l}\text { Total physician attitude about acceptance and } \\
\text { implementation of EHR. }\end{array}$ & $0.46 \pm 4.03$ & 5.03 & 0.001 \\
\hline
\end{tabular}

Table 4: Physician Attitude about EHR implementation $(n=70)$.

usefulness was significant relationship but between sex and responders attitude wasn't any significant relationship (Table 4).

\section{Discussion}

It showed that EHR acceptance is high between faculty and house staff. $88 \%$ of house staff and $64.7 \%$ of faculty prefer EHR according to paper record. Although the acceptance was high in both groups but this score was found more in house staff. In our research, there was no significant difference between faculty and non-faculty as a disparity has been found in the previous studies that may be due to the difference in knowledge between two groups [7].

Management support in our research had a mean score $4.01 \pm 0.60$. Morton and Wiedenbeck [17] in their study report had 3.65 mean score for management support. Also Jabraily et al. [10] computed 3.042 mean score for user positive attitude to the EHR implementation. So a comparison of this result and compatibility with our result, we can say management support to the EHR implementation in our research society is optimal.

Physician involvement in our research had $4.06 \pm 0.51$ mean score. Morton and Elizabeth [13] evaluates 3.83 mean score for this factor. The result shows that responders know the importance of involvement in EHR implementation.

Mean score for physician training was $4.04 \pm 0.51$. In Peled study, $72 \%$ of students who had just completed an ambulatory medicine clerkship, report that they can ask more patient history questions because of EHR prompt response and also they can order more clinical preventive services. Most of medical students state that EHR improves the documentation process. There are some evidences that physician may not be able to acquire special communication skills of EHR automatically so this would demand the faculty member to play a role to teach the skills to future physicians [18]. Jabraily et al. [10] in his research report provides the mean score of 2.87 for computer skills, so we can conclude that the physician training before EHR implementation is necessary.

Physician autonomy in using EHR had a mean score of $3.20 \pm 0.61$ in our study. Walter and Lopez [19] in a study shows that perceived threats about professional autonomy was significant and had a negative effect on perceived usefulness of information technology and intention to use technology by physicians. Although we have some similar study in this scope with inconsistent result, but according to our study result, we can say that EHR doesn't limit physician autonomy.

Mean score for effects of EHR on physician-patient relationship in our study was $2.33 \pm 0.82$. Loomis et al. [20] manifests that physician who didn't use EHR in comparison with physicians who made use of
EHR; significantly had less belief on EHR ability to increase service quality at offices $(52.4 \%$ vs $80.9 \%)$.

According to this result we can conclude that EHR implementation would not have negative effect on physician-patient relationship.

Perceived usefulness of EHR had a mean score about $3.91 \pm 0.46$ in our research. According to physicians in comparison with other information system users are more pragmatic and also search more for their application programs that can be compatible with their tasks. Hence, they stated that physicians may know the usefulness of system in practice [14]. In Loomis et al. [20] study, physicians who use EHR had significantly less belief on usefulness of current electronic health records (51.5\% vs $92 \%)$.

According to Bloom and Huntington [21] study, faculty members and residents state 13 minutes for documentation on each patient's information. All persons' attitude clarify that EHR has negative effect on patient care but in our research we have $4.03 \pm 0.46$ mean score for this item, that it shows that most physicians agree with EHR implementation.

Since physicians are key elements on health care delivery systems, therefore, they have significant role to perform in successful implementation of EHR. According to this study, physician's attitude about EHR acceptance is in an optimal situation. Thus for facilitating EHR implementation, involvement of physician during EHR planning and development phase must be considered.

\section{References}

1. Jasmine C (2009) The Impact of Usability on Clinician Acceptance of a Health Information System.

2. Hayrinen K, Saranto K, Nykanen P (2008) Definition, structure, content, use and impacts of electronic health records: a review of the research literature. Int J Med Inform 77: 291-304.

3. Haslina M, Sharifah Mastura SM (2005) Acceptance Model of Electronic Medical Record. Journal of Advancing Information and Management Studies 2: 75-92.

4. Thakkar M, Davis DC (2006) Risks, Barriers, and Benefits of EHR Systems: A Comparative Study Based on Size of Hospital. Perspect Health Inf Manag 14: $3: 5$.

5. Carayon P, Cartmill R, Blosky MA, Brown R, Hackenberg M, et al. (2011) ICU nurses' acceptance of electronic health records . J Am Med Inform Assoc 18: 812-819.

6. Deutsch E, Duftschmid G, Dorda W (2010) Critical areas of national electronic health record programs-is our focus correct? Int J Med Inform 79: 211-222.

7. Hier DB, Rothschild A, LeMaistre A, Keeler J (2004) Differing faculty and house staff acceptance of an electronic health record one year after implementation. Stud Health Technol Inform 107: 6571300-1303.

8. Holden RJ (2010) Physicians' beliefs about using EMR and CPOE: in pursuit of a contextualized understanding of health IT use behavior. Int J Med Inform 79: $71-80$.

9. Bleich HL, Slack WV (2010) Reflections on electronic medical records: when doctors will use them and when they will not. Int J Med Inform 79: 1-4.

10. Jabraily MAM, Hajavi A, Gohari M, Sedghi JM, Zare FZ (2010) Electronic Health Records: assessment of Human resources readiness Health management. 39: $17-24$

11. Al-Azmi SF, Al-Enezi N, Chowdhury RI (2009) Users' attitudes to an electronic medical record system and its correlates: a multivariate analysis. HIM J 38: 33-40.

12. Wilkins MA (2009) Factors influencing acceptance of electronic health records in hospitals. Perspectives Health Information Management 6: 1f.

13. Morton Elizabeth M (2008) Use and Acceptance of an Electronic Health Record: Factors Affecting Physician Attitudes. 
Citation: Alipour J, Erfannia L, Karimi A, Aliabadi A (2013) Electronic Health Record Acceptance: A Descriptive Study in Zahedan, Southeast Iran. J Health Med Inform 4: 120. doi:10.4172/2157-7420.1000120

14. Fenton SH, Giannangelo K, Stanfill M (2006) Essential people skills for EHR implementation success. J AHIMA 77: 60A-60D.

15. Evaluation of electronic health record in Iran: Iranian majlis research center.

16. Hamidifar, Mahbod (2008) Adoption of electronic patient records by Iranian hospitals staff.

17. Morton ME, Wiedenbeck S (2010) EHR acceptance factors in ambulatory care: a survey of physician perceptions. Perspect Health Inf Manag 7: 1c

18. Peled JU, Sagher O, Morrow JB, Dobbie AE (2009) Do electronic health records help or hinder medical education? PLoS Med.
19. Walter Z, Lopez MS (2008) Physician acceptance of information technologies: Role of perceived threat to professional autonomy. Decision Support Systems 46: $206-215$

20. Loomis GA, Ries JS, Saywell RM Jr, Thakker NR (2002) If electronic medical records are so great, why aren't family physicians using them? J Fam Pract 51: 636-641.

21. Bloom MV, Huntington MK (2010) Faculty, resident, and clinic staff's evaluation of the effects of EHR implementation. Fam Med 42: 562-566. 